\title{
Hospitalization timeliness of patients with myocardial infarction
}

\author{
Tengiz Verulava $^{1^{\star}}$, Tamar Maglakelidze $^{1}$, Revaz Jorbenadze $^{2}$ \\ ${ }^{1}$ Health Policy and Insurance Institute, Ilia State University, Tbilisi, Georgia \\ ${ }^{2}$ G. Chapidze Emergency Cardiology Center, Tbilisi, Georgia
}

\begin{abstract}
Timely self-help measures and management of acute myocardial infarction (AMI) improve the disease outcomes. Management of AMI is most beneficial if applied within two hours from the onset of symptoms. However, many patients with AMI do not benefit because of seeking medical care late. The aim of research was to study to timeliness of prehospital phase of treatment and investigate the causes of postponement in seeking treatment among patients with AMI. Within the framework of the quantitative research, the beneficiaries were interviewed with a structured questionnaire. The majority of patients did not have necessary pre-hospital self-help measures, and called to the doctor when it was already late. Only $51 \%$ of patients appeal to self-help measures and $28 \%$ arrived at hospital within 2 hours after the onset of symptoms. $65 \%$ of the patients misunderstand the nature of pain. $28 \%$ of patients had pain resistance behavior.

There is low awareness among the patients about the main symptoms of the disease and importance of call for an emergency in timely manner. Consequently, only a small part has been hospitalized in the first hours. Low development of the primary health care system in Georgia has negative impact on the quality of medical surveillance of the patient. It is recommended to improve institute of the family physician on the country scale, which will help to conduct continuous surveillance of the population, to increase patient awareness regarding basic symptoms of the disease.
\end{abstract}

Key Words: Myocardial infarction, hospitalization timeliness, family physician

\section{Introduction}

Cardiovascular diseases are recognized as the leading causes of morbidity and mortality in Georgia and worldwide $(1,2)$. Most cardiovascular diseases can be prevented by addressing behavioral risk factors such as tobacco use, unhealthy diet, obesity, physical inactivity and harmful use of alcohol (3). People with cardiovascular disease or who are at high cardiovascular risk need early detection and management using counseling and medicines, as appropriate (4). Being a life threatening manifestation of cardiovascular diseases, acute myocardial infarction (AMI) needs early recognition and supervision. It should be noted that approximately one-third of deaths from AMI occur within first few hours of onset of symptoms and mostly before the patient's hospitalization (5).

The time between symptom onset and calling for professional help, the "decision time", is still the largest contributor to the total time postponement [6]. Patients with cardiac disease mostly lose a lot of valuable time, because they cannot realize the significance of symptoms and do not visit a doctor timely (7). A timely visit to physician increases the chance of patient survival and can result in dramatically improved patient clinical outcomes (810).

Studies confirm that, Management of AMI is most beneficial if applied within two hours from the onset of symptoms (11-15). However, many patients with AMI do not benefit because of seeking medical care late. Around $85 \%$ of heart damage occurs within the first two hours of a heart attack and only $10 \%$ receive therapy within the first critical hour (16); 50\% patients with AMI seek medical care after 2 hours and more and one-quarter are referred to the medical center after 6 hours; As a result, majority of patients die at pre-hospital stage (17). The majority of the patients does not have knowledge about self-help measures and administration of AMI, misunderstand the significance of their symptoms and therefore, they have lack incentive to change their behavior (18, 19).

The aim of research was to study timeliness of prehospital phase of treatment and investigate the causes of postponement in seeking treatment among patients with AMI. 


\section{Materials and methods}

This cross-sectional study was conducted among all patients with confirmed AMI admitted to the Acad. G. Chapidze Emergency Cardiology Center. Cardiology hospital was selected by the volume of treated patients.

In the framework of quantitative research, we interviewed 400 patients, who were admitted to Cardiology Center with the diagnosis of AMI, between April 2016 and December 2004. The study protocol was approved by the standard ethics of Cardiology Center ethical committee and all participants gave informed consent and were interviewed face to face with a particular structured questionnaire

Patients were pain-free and hemodynamically stable at the time of interview. Patients who had a cardiac arrest before admission and those who had cognitive disorders were excluded from the study. Ten patients were excluded due to the lack of reliable data.

Total prehospital postponement was the time (in minutes) from symptom onset to arrival at the emergency department of Cardiology Center.

Study variables included age, gender, marital status, education level, previous history of health problems, the presence of diabetes, hypertension, angina, clinical manifestation of patients at the admission time, and first patient's reactions to myocardial infarction symptoms.

Data entry and analysis were all done by using software SPSS (Statistical Package for the Social Sciences) version 16.

\section{Results}

In order to study the influence of social factors on the timeliness of self-help measures of myocardial infarction patients, pre-hospital stage analysis was conducted. For this, period from first symptoms (chest pain arising) of myocardial infarction till beginning of self-help measures was studied. The comparison of Period of time passed from the beginning of chest pain arising till the beginning of self-help measures by sociodemographic and clinical characteristics was presented in Table 1.

According to the study, $14 \%$ of patients appeal to self-help measures within 10 minutes after the beginning of chest pain arising, 51\% - within 2 hours and $36 \%$ - after 12 hours.
Among patients, those who applied to self-help measures within 2 hours, it was found that $50 \%$ of them were 50-65 years old patients. Regarding residence and marital status, it was found that there were statistically significant differences between urban and rural, married and unmarried patients who appeal to self-help measures: 66\% were urban and $34 \%$ rural, $70 \%$ married and $30 \%$ unmarried, respectively.

Regarding clinical characteristics, $56 \%$ of patients, who applied to self-help measures within 2 hours, had history of previous angina, $62 \%$ of patients hypertension, and 35\% patients - diabetes (Table 1).

At pre-hospital stage only half of patients with myocardial infarction got adequate assistance before the call to emergency. In most cases insufficient and untimely pharmacotherapy, as well as late appeal in the hospital and as a result delayed hospitalization was revealed.

The comparison of prehospital postponement times by sociodemographic and clinical characteristics of the patients was presented in Table 2. According to the study, $28 \%$ arrived at hospital within 2 hours after the onset of symptoms.

Among patients, those who call to emergency within 2 hours from the beginning of medical symptoms, $57 \%$ were aged patients ( $>65$ years old) and 65\% were from urban areas. Regarding educational, marital and occupational status, it was found that there were statistically significant differences between patients who call to emergency within 2 hours from the beginning of symptoms and those who postponemented seeking medical care; $72 \%$ were married and $28 \%$ were unmarried, $70 \%$ were university/above and $30 \%$ below university; $54 \%$ were professional, $26 \%$ self-employed and $20 \%$ unemployed.

Regarding clinical characteristics, $83 \%$ of patients, who call to emergency within 2 hours from the beginning of symptoms, had history of previous angina, $75 \%$ of patients - hypertension, and $76 \%$ patients - diabetes (Table 2).

According to the table 3, only $17 \%$ of patients without ischemic heart disease in medical history (first myocardial infarction) call to emergency within the 2 hours, which passed from the beginning of medical symptoms. Among the patients, with ischemic heart disease in medical history, $83 \%$ of patients call to emergency within the 2 hours from the beginning of heart attack. 
Table 1. Period of time passed from the beginning of chest pain arising till the beginning of self-help measures, in relation to baseline and demographic characteristics of the participants

\begin{tabular}{|c|c|c|c|c|c|c|c|c|c|}
\hline Variables & $\begin{array}{c}\text { All } \\
(n=400)\end{array}$ & $\begin{array}{l}<10 \min \\
(\mathrm{n}=57) \\
=14 \%\end{array}$ & $\begin{array}{c}11-40 \\
\min \\
(\mathrm{n}=70) \\
=11 \%\end{array}$ & $\begin{array}{c}41-60 \\
\min \\
(\mathrm{n}=14) \\
=4 \%\end{array}$ & $\begin{array}{c}1-2 \\
\text { hours } \\
(\mathrm{n}=63) \\
=16 \%\end{array}$ & $\begin{array}{c}3-6 \\
\text { hours } \\
(\mathrm{n}=20) \\
=5 \%\end{array}$ & $\begin{array}{c}7-12 \\
\text { hours } \\
(\mathrm{n}=26) \\
=7 \%\end{array}$ & $\begin{array}{c}>12 \\
\text { hours } \\
(\mathrm{n}=150) \\
=38 \%\end{array}$ & $\begin{array}{c}<2 \\
\text { hours } \\
(\mathrm{n}=204) \\
=51 \%\end{array}$ \\
\hline \multicolumn{10}{|l|}{ Age } \\
\hline$<50$ years' old & $84(21)$ & $12(21)$ & $11(16)$ & $1(7)$ & $13(21)$ & $2(10)$ & $3(12)$ & $42(28)$ & $37(18)$ \\
\hline 50-65 years' old & $205(51)$ & $28(49)$ & $36(51)$ & $7(50)$ & $31(49)$ & $14(70)$ & $15(58)$ & $74(49)$ & $102(50)$ \\
\hline$>65$ years' old & $111(28)$ & $17(30)$ & $23(33)$ & $6(43)$ & $19(30)$ & $4(20)$ & $8(31)$ & $34(23)$ & $65(32)$ \\
\hline \multicolumn{10}{|l|}{ Sex } \\
\hline Male & $296(74)$ & $19(68)$ & $25(76)$ & $4(57)$ & $58(84)$ & $17(85)$ & $23(88)$ & 150(100) & $106(51)$ \\
\hline Female & $104(26)$ & $38(32)$ & $45(24)$ & $10(43)$ & $5(16)$ & $3(15)$ & $3(12)$ & $0(0)$ & $99(49)$ \\
\hline \multicolumn{10}{|l|}{ Residence } \\
\hline Urban & $274(69)$ & $34(60)$ & $45(64)$ & $10(71)$ & $46(73)$ & $14(70)$ & $17(65)$ & $108(72)$ & $135(66)$ \\
\hline Rural & $126(31)$ & $23(40)$ & $25(36)$ & $4(29)$ & $17(27)$ & $6(30)$ & $9(35)$ & $42(28)$ & $69(34)$ \\
\hline \multicolumn{10}{|l|}{ Marital status } \\
\hline Married & $318(80)$ & $43(75)$ & $49(70)$ & $9(64)$ & $41(65)$ & $13(65)$ & $18(69)$ & $145(97)$ & $142(70)$ \\
\hline $\begin{array}{l}\text { Unmarried } \\
\text { (widow, single, } \\
\text { or divorced) }\end{array}$ & $82(21)$ & $14(25)$ & $21(30)$ & $5(36)$ & $22(35)$ & $7(35)$ & $8(31)$ & $5(3)$ & $62(30)$ \\
\hline \multicolumn{10}{|l|}{ Educational level } \\
\hline University/above & $221(55)$ & $31(54)$ & $42(60)$ & $9(64)$ & $33(52)$ & $14(70)$ & $15(58)$ & $77(51)$ & $115(56)$ \\
\hline $\begin{array}{l}\text { Below university } \\
\text { Illiterate }\end{array}$ & $179(45)$ & $26(46)$ & $28(40)$ & $5(36)$ & $30(48)$ & $6(30)$ & $11(42)$ & $73(49)$ & $89(44)$ \\
\hline \multicolumn{10}{|l|}{ Occupation } \\
\hline Professional & $94(24)$ & $16(28)$ & $34(49)$ & $8(57)$ & $5(8)$ & $12(60)$ & $10(38)$ & $9(6)$ & $63(31)$ \\
\hline Self-employed & $128(32)$ & $24(42)$ & $19(27)$ & $3(21)$ & $31(49)$ & $4(20)$ & $8(31)$ & $36(24)$ & $77(38)$ \\
\hline Unemployed & $178(45)$ & $17(30)$ & $17(24)$ & $3(21)$ & $27(43)$ & $4(20)$ & $8(31)$ & $105(70)$ & $64(31)$ \\
\hline \multicolumn{10}{|l|}{ Risk factors } \\
\hline \multicolumn{10}{|l|}{ Hypertension } \\
\hline Yes & $238(59.5)$ & $39(68)$ & $41(59)$ & $9(64)$ & $37(59)$ & $12(60)$ & $16(62)$ & $84(56)$ & $126(62)$ \\
\hline No & $162(40.5)$ & $18(32)$ & $29(41)$ & $5(36)$ & $26(41)$ & $8(40)$ & $10(38)$ & $66(44)$ & $78(38)$ \\
\hline \multicolumn{10}{|l|}{ Diabetes } \\
\hline Yes & $152(38)$ & $19(33)$ & $29(41)$ & $5(36)$ & $19(30)$ & $9(45)$ & $12(46)$ & $59(39)$ & $72(35)$ \\
\hline No & $248(62)$ & $47(82)$ & $41(59)$ & $9(64)$ & $44(70)$ & $11(55)$ & $14(54)$ & $91(61)$ & $141(65)$ \\
\hline \multicolumn{10}{|l|}{ Previous angina } \\
\hline Yes & $133(33)$ & $36(63)$ & $45(64)$ & $9(64)$ & $25(40)$ & $8(40)$ & $6(23)$ & $4(3)$ & $115(56)$ \\
\hline No & $267(67)$ & $21(37)$ & $25(36)$ & $5(36)$ & $38(60)$ & $12(60)$ & $20(77)$ & $146(97)$ & $89(44)$ \\
\hline
\end{tabular}

Regarding the understanding of the cause of pain, $35 \%(n=138)$ of the patients associated it with a heart problem and $65 \%(n=262)$ of the patients misunderstand the nature of pain (temporary discomfort, a stomach problem...)

According to the study, as shown in Table 4, about $72 \%$ of patients seek medical advice. $28 \%$ of patients had pain resistance behavior. They tried to reduce the pain (taking water, medicine), or conceal the pain (preserving calm).

\section{Discussion}

Treatment of myocardial infarction with maximum efficiency can only be reached if patients apply for medical care timely and if their (or family members) actions are competent before doctor arrives. The survey revealed that the majority of patients did not have necessary self-help measures, and called to the doctor when it was already late, after approximately 12 hours from the first symptoms of the disease. 
Table 2. Period of time passed from the beginning of symptoms till the call to emergency, in relation to baseline and demographic characteristics of the participants

\begin{tabular}{|c|c|c|c|c|c|c|c|c|c|}
\hline Variables & $\begin{array}{c}\text { All } \\
(n=400)\end{array}$ & $\begin{array}{l}<10 \min \\
(\mathrm{n}=12) \\
=3 \%\end{array}$ & $\begin{array}{c}11-40 \\
\min \\
(\mathrm{n}=27) \\
=7 \%\end{array}$ & $\begin{array}{c}41-60 \\
\min \\
(\mathrm{n}=11) \\
=3 \%\end{array}$ & $\begin{array}{c}1-2 \\
\text { hours } \\
(\mathrm{n}=60) \\
=15 \%\end{array}$ & $\begin{array}{c}3-6 \\
\text { hours } \\
(\mathrm{n}=127) \\
=32 \% \\
\end{array}$ & $\begin{array}{c}7-12 \\
\text { hours } \\
(\mathrm{n}=112) \\
=28 \%\end{array}$ & $\begin{array}{l}>12 \\
\text { hours } \\
(\mathrm{n}=51) \\
=13 \%\end{array}$ & $\begin{array}{c}<2 \\
\text { hours } \\
(\mathrm{n}=110) \\
=28 \% \\
\end{array}$ \\
\hline \multicolumn{10}{|l|}{ Age } \\
\hline$<50$ years' old & $84(21)$ & $1(8)$ & $2(7)$ & $1(9)$ & $8(13)$ & $38(30)$ & $18(16)$ & $16(31)$ & $12(11)$ \\
\hline 50-65 years' old & $205(51)$ & $4(33)$ & $8(30)$ & $2(18)$ & $21(35)$ & $102(80)$ & $40(36)$ & $28(55)$ & $35(32)$ \\
\hline$>65$ years' old & $111(28)$ & $7(58)$ & $17(63)$ & $8(73)$ & $31(52)$ & $28(22)$ & $14(13)$ & $6(12)$ & $63(57)$ \\
\hline \multicolumn{10}{|l|}{ Sex } \\
\hline Male & $296(74)$ & $5(42)$ & $13(48)$ & $4(36)$ & $22(37)$ & $95(75)$ & $107(96)$ & $50(98)$ & $44(40)$ \\
\hline Female & $104(26)$ & $7(58)$ & $14(52)$ & $7(64)$ & $38(63)$ & $32(25)$ & $5(4)$ & $1(2)$ & $66(60)$ \\
\hline \multicolumn{10}{|l|}{ Residence } \\
\hline Urban & $274(69)$ & $9(75)$ & $17(63)$ & $8(73)$ & $37(62)$ & $92(72)$ & $73(65)$ & $38(75)$ & $71(65)$ \\
\hline Rural & $126(31)$ & $3(25)$ & $10(37)$ & $3(27)$ & $23(38)$ & $35(28)$ & $39(35)$ & $13(25)$ & $39(35)$ \\
\hline \multicolumn{10}{|l|}{ Marital status } \\
\hline Married & $318(80)$ & $10(83)$ & $19(70)$ & $9(82)$ & $41(68)$ & $108(85)$ & 104(93) & $27(53)$ & $79(72)$ \\
\hline $\begin{array}{l}\text { Unmarried } \\
\text { (widow, single, } \\
\text { or divorced) }\end{array}$ & $82(21)$ & $2(17)$ & $8(30)$ & $2(18)$ & $19(32)$ & $19(15)$ & $8(7)$ & $24(47)$ & $31(28)$ \\
\hline \multicolumn{10}{|l|}{ Educational level } \\
\hline University/above & $221(55)$ & $9(75)$ & $18(67)$ & $7(64)$ & $43(72)$ & $78(61)$ & $42(38)$ & $24(47)$ & $77(70)$ \\
\hline $\begin{array}{l}\text { Below university } \\
\text { Illiterate }\end{array}$ & $179(45)$ & $3(25)$ & $9(33)$ & $4(36)$ & $17(28)$ & $49(39)$ & $70(63)$ & $27(53)$ & $33(30)$ \\
\hline \multicolumn{10}{|l|}{ Occupation } \\
\hline Professional & $94(24)$ & $7(58)$ & $14(52)$ & $6(55)$ & $32(53)$ & $16(13)$ & $12(11)$ & $7(14)$ & $59(54)$ \\
\hline Self-employed & $128(32)$ & $3(25)$ & $8(30)$ & $3(27)$ & $15(25)$ & $61(48)$ & $29(26)$ & $9(18)$ & $29(26)$ \\
\hline Unemployed & $178(45)$ & $2(17)$ & $5(19)$ & $2(18)$ & $13(22)$ & $50(39)$ & $71(63)$ & $35(69)$ & $22(20)$ \\
\hline \multicolumn{10}{|l|}{ Risk factors } \\
\hline \multicolumn{10}{|l|}{ Hypertension } \\
\hline Yes & $238(59.5)$ & $8(67)$ & $20(74)$ & $10(91)$ & $46(77)$ & $49(39)$ & $70(63)$ & $35(69)$ & $84(76)$ \\
\hline No & $162(40.5)$ & $4(33)$ & $7(26)$ & $1(9)$ & $14(23)$ & $78(61)$ & $42(38)$ & $16(31)$ & $26(24)$ \\
\hline \multicolumn{10}{|l|}{ Diabetes } \\
\hline Yes & $152(38)$ & $11(92)$ & $21(78)$ & $8(73)$ & $42(70)$ & $21(17)$ & $29(26)$ & $20(39)$ & $82(75)$ \\
\hline No & $248(62)$ & $1(8)$ & $6(22)$ & $3(27)$ & $18(30)$ & $106(83)$ & $83(74)$ & $31(61)$ & $28(25)$ \\
\hline \multicolumn{10}{|l|}{ Previous angina } \\
\hline Yes & $133(33)$ & $12(100)$ & $22(81)$ & $9(82)$ & $48(80)$ & $32(25)$ & $2(2)$ & 8 (16) & 91 (83) \\
\hline No & $267(67)$ & $0(0)$ & $5(19)$ & $2(18)$ & $12(20)$ & $95(75)$ & $110(98)$ & $43(84)$ & $19(17)$ \\
\hline
\end{tabular}

Table 3. Period of time passed from the beginning of symptoms till the call to emergency, in relation to baseline and demographic characteristics of the participants

\begin{tabular}{|c|c|c|c|}
\hline Variables & $\begin{array}{c}\text { All }(n=400) \\
\text { Men }(n=296) \\
\text { Women }(n=104)\end{array}$ & $\begin{array}{l}\text { Early arrival } \leq 2 \text { hours } \\
\qquad(\mathrm{n}=110) 28 \%\end{array}$ & $\begin{array}{l}\text { Prehospital postponement } \\
>2 \text { hours }(\mathrm{n}=290) 72 \%\end{array}$ \\
\hline $\begin{array}{l}\text { Without a history of ischemic heart } \\
\text { disease (first myocardial infarction }\end{array}$ & $133(33)$ & $91(83)$ & $42(14)$ \\
\hline Male & $109(82)$ & $77(63)$ & $32(76)$ \\
\hline Female & $24(18)$ & $14(37)$ & $10(24)$ \\
\hline $\begin{array}{l}\text { With ischemic heart diseases in } \\
\text { medical history }\end{array}$ & $267(67)$ & $19(17)$ & $248(86)$ \\
\hline Male & $187(70)$ & $12(63)$ & $175(71)$ \\
\hline Female & $80(30)$ & $7(37)$ & $73(29)$ \\
\hline
\end{tabular}


Table 4. Prehospital postponement in relation to the acute perception of symptoms

\begin{tabular}{lccc}
\hline Acute perception of symptoms & $\begin{array}{c}\text { All }(\mathrm{n}=400) \\
\text { Men }(\mathrm{n}=296) \\
\text { Women }(\mathrm{n}=104)\end{array}$ & $\begin{array}{c}\text { Early advent } \leq 2 \text { hours } \\
(\mathrm{n}=110) 28 \%\end{array}$ & $\begin{array}{c}\text { Prehospital postponement }> \\
2 \text { hours }(\mathrm{n}=290) 72 \%\end{array}$ \\
\hline Understanding of the cause of pain & & & $87(30)$ \\
\hline Associate it to heart problem & $138(35)$ & $51(46)$ & $203(70)$ \\
Misunderstand the nature of pain & $262(65)$ & $59(54)$ & $209(72)$ \\
\hline Response during pain incidence & & $78(71)$ & $81(28)$ \\
\hline Seek medical advice & $287(72)$ & $32(29)$ & \\
Pain resistance behavior & $113(28)$ & & \\
\hline
\end{tabular}

According to the study, $67 \%$ of patients are without a history of ischemic heart disease, respectively, they reported that this was the first episode of AMI. This fact may explain why only $35 \%$ of the patients associated the pain with a heart problem.

As it is known, process and outcome of the disease depend on the timely self-help measures, medication, appeal to the hospital and quality of care. The majority $(70 \%)$ of patients who postponed seeking medical care for $>2$ hours misunderstand the nature of symptoms, and $28 \%$ showed pain resistant behaviors. The study confirms that patients who misunderstand the pain as cardiovascular symptom and respectively, expressed pain resistance behaviors, took longer time to decide to seek medical care and to call emergency (Table 4). These results were consistent with the findings of Ghazawy et al. (16). Thus, understanding of the cause of pain and response during pain incidence were significant predictors in prehospital delay time.

According to study results, older people $(>65$ years old) are more likely seeking medical care compared to youngers. This could be due to older people are more covered by state health care programs (Universal State Healthcare Program in Georgia) and thus, have access to more healthcare services. It should be noted that no significant differences in delay times between men and women.

The results of the survey show that educational level has important role for prehospital postponement. Especially important is low awareness of patients regarding the basic symptoms of the disease, as well as self-help measures that are necessary when these symptoms arise. The lack of information is the main reason for late appeal to the hospital. From patients without ischemic heart disease in medical history (first myocardial infarction), only small part knew about the importance of timeliness to appeal to the hospital.

Patients, without ischemic heart disease in medical history (first myocardial infarction) who were not aware regarding timeliness to call for a doctor, only small part from them were hospitalized during first hours of the disease, while majority of informed patients were hospitalized during the first hours of the disease.

Based on the above, it is important that patient know how to prevent heart disease, how to recognize symptoms of a heart attack, how to take action for immediate medical help. In this regard, it should be taken into consideration that the primary care system in Georgia is not developed at the appropriate level $(20,21)$. Patients are not dynamically and continuously surveilled by family physicians (22,23). Family physicians do not inform patients about the main symptoms of the disease, self-help measures and importance of call for an ambulance in timely manner (24-26).

According to the study, employment status has important role for prehospital postponement. Among unemployed patients only $31 \%$ applied to self-help measures, and only $20 \%$ call to emergency within 2 hours from the beginning of symptoms. This could be explained by the high cost of health care services as the unemployed persons were not covered by State Healthcare Program or maybe not insured by the private insurance.

In conclusion, late apply to the hospital of AMI patients shows that the majority of patients apply for medical service lately and very seldom in first hour. More than half of patients did not receive adequate self-help measures when the first disease symptoms occurred.

The majority of the patients do not have knowledge about myocardial infarction self-help measures and optimal time to call emergency. As a result, even less 
than half of the patients were hospitalized during first hours from the beginning of symptoms.

Efficiency of the treatment, timeliness of self-help measures and awareness of patient with AMI significantly depends on the level of primary health care in the country. Low development of the primary health care system in Georgia has negative impact on the quality of medical surveillance of the patient. It is recommended to improve institute of the family physician on the country scale, which will help to conduct continuous surveillance of the population, to increase patient awareness regarding basic symptoms of the disease.

Study limitations; our study has several limitations. We studied a relatively small sample of patients with AMI. Patients who did not seek treatment or died before arriving at a hospital were not included in the study. We were not able to include data from patients who were hemodynamically unstable during the interview period. Although Acad. G. Chapidze Emergency Cardiology Center is a high-volume center, the results reflect the data of a single center, which makes it difficult to draw conclusions about the general population.

\section{References}

1. Townsend N, Wilson L, Bhatnagar P, Wickramasinghe K, Rayner M, Nichols M. Cardiovascular disease in Europe: epidemiological update 2016. Eur Heart J 2016; 37: 3232-3245.

2. Health Care, Statistical Yearbook. Ministry of Labour, Health and Social Affairs of Georgia. National Center for Disease Control and Public Health 2015.

3. Mendis S, Puska P, Norrving B. Global Atlas on Cardiovascular Disease Prevention and Control. Geneva: World Health Organization 2011.

4. Smith SC Jr, Benjamin EJ, Bonow RO, et al. AHA/ACCF secondary prevention and risk reduction therapy for patients with coronary and other atherosclerotic vascular disease: 2011 update: a guideline from the American Heart Association and American College of Cardiology Foundation endorsed by the World Heart Federation and the Preventive Cardiovascular Nurses Association. J Am Coll Cardiol 2011; 58: 2432-2446.

5. Chambless L, Keil U, Dobson A, et al. Population versus clinical view of case fatality from acute coronary heart disease: results from the WHO MONICA Project 1985-1990. Multinational MONItoring of Trends and Determinants in CArdiovascular Disease. Circulation 1997; 96: 38493859.
6. Gilbert JA, Clancy M. Patient knowledge of thrombolysis in acute myocardial infarction. Emerg Med J 2003; 20: 52-53.

7. Cowie MR, Anker SD, Cleland JG, et al. Improving care for patients with acute heart failure: before, during and after hospitalization. European Journal of Heart Failure 2014; 1: 110-145.

8. Cannon CP, Gibson CM, Lambrew CT, et al. Relationship of symptom-onset-to-balloon time and door-to-balloon time with mortality in patients undergoing angioplasty for acute myocardial infarction. JAMA 2000; 283: 2941-2947.

9. De Luca G, Suryapranata H, Ottervanger JP, Antman EM. Time delay to treatment and mortality in primary angioplasty for acute myocardial infarction: every minute of delay counts. Circulation 2004; 109: 1223-1225.

10. Magid DJ, Wang Y, Herrin J, et al. Relationship between time of day, day of week, timeliness of reperfusion, and in-hospital mortality for patients with acute ST-segment elevation myocardial infarction. JAMA 2005; 294: 803-812.

11. De Luca G, Suryapranata H, Ottervanger JP, Antman EM. Time delay to treatment and mortality in primary angioplasty for acute myocardial infarction: every minute of delay counts. Circulation 2004; 109: 1223-1225.

12. Avorn J, Knight E, Ganz DA, Schneeweiss S. Therapeutic delay and reduced functional status six months after thrombolysis for acute myocardial infarction. Am J Cardiol 2004; 94: 415-420.

13. Lundergan CF, Reiner JS, Ross AM. How long is too long? Association of time delay to successful reperfusion and ventricular function outcome in acute myocardial infarction: the case for thrombolytic therapy before planned angioplasty for acute myocardial infarction. Am Heart J 2002; 144 : 456-462.

14. Boersma E, Maas AC, Deckers JW, Simoons ML. Early thrombolytic treatment in acute myocardial infarction: reappraisal of the golden hour. Lancet 1996; 348: 771-775.

15. Antman EM, Anbe DT, Armstrong PW, et al. ACC/AHA guidelines for the management of patients with ST-elevation myocardial infarctionexecutive summary. A report of the American College of Cardiology/American Heart Association Task Force on Practice Guidelines (Writing Committee to revise the 1999 guidelines for the management of patients with acute myocardial infarction). J Am Coll Cardiol 2004; 44: 671-719.

16. Ghazawy ER, Seedhom AE, Mahfouz EM. Predictors of Delay in Seeking Health Care among Myocardial Infarction Patients, Minia District, Egypt. Adv Prev Med 2015; 2015: 342361.

17. Schmidt C. Early heart attack care. The university of Florida Academic Heart Center. 2012 
18. Aschermann M, Widimsky P. I have an acute myocardial infarction: open my coronary artery, stent it and keep full flow. Eur Heart J 2002; 23: 913-916.

19. Nehme Z, Andrew E, Bernard S, et al. Impact of a public awareness campaign on out-of-hospital cardiac arrest incidence and mortality rates. Eur Heart J 2017; 38: 1666-1673.

20. Verulava T, Jincharadze N, Jorbenadze R. Role of Primary Health care in re-hospitalization of patients with heart failure. Georgian Med News 2017; 264: 135-139.

21. Verulava T, Maglakelidze T. Health Financing Policy in the South Caucasus: Georgia, Armenia, Azerbaijan. Bulletin of the Georgian National Academy of Sciences 2017; 11: 143-150.

22. Verulava T, Jorbenadze R, Barkalaia T. 2017. Introduction of universal health program in
Georgia: Problems and Perspectives. Georgian Med News 2017; 262: 116-120.

23. Verulava T, Gabuldani M. Accessibility of Urgent Neurosurgery Diseases by the State Universal Healthcare Program in Georgia (country). Gazi Medical Journal 2015; 26: 42-45.

24. Verulava T, Adeishvili I, Maglakelidze T. Home Care Services for Elderly People in Georgia. Home Health Care Management Practice 2016; 1-8.

25. Verulava T, Sibashvili N. Accessibility to Psychiatric Services in Georgia. Journal of Psychiatry: Open Access 2015; 18: 1-5.

26. Verulava T. Access to Medicines within the State Health Insurance Program for Pension Age Population in Georgia (country). HealthMED 2014; 8: 1078-1082. 